\title{
Perfusion SPECT in patients with suspected pulmonary embolism: how much sensitivity is needed to keep patients alive?
}

\author{
Carl Schuemichen
}

Published online: 8 June 2013

(C) Springer-Verlag Berlin Heidelberg 2013

Combined use of ventilation (V) and perfusion (P) scintigraphy for the diagnosis of acute and chronic thromboembolic pulmonary embolism (PE) has been well established for nearly 50 years, and is also anchored in the current European guidelines $[1,2]$. The intention in using this technique is to differentiate between local V/P mismatch associated with embolic disease and local V/P match related to obstructive airway disease. This functional approach to the diagnosis of $\mathrm{PE}$ is needed mostly in elderly patients, since the incidence of obstructive airway disease increases with age. With Ponly scintigraphy the rate of false-positive findings increases to an unacceptable $47 \%$ even with SPECT/CT [3]. Despite well-documented advantages, V scintigraphy has not become popular in many European countries for various reasons: availability (Italy), expense, fear of radioactive contamination, and lack of quality control (Germany).

In 2005, P-only scintigraphy was performed in $89 \%$ of all lung examinations in Italy, in $72.4 \%$ in Germany, in $44.1 \%$ in Spain, in $21.3 \%$ in the UK, and in only $12.4 \%$ in France [4]. Proof or exclusion of PE was intended in most of these studies. Two years later, following the success of CT pulmonary angiography (CTPA), the number of $\mathrm{V}$ scintigraphies in Germany increased by $25 \%$, but lung examinations went down by $37 \%$. In Italy, morphological attributes (PISAPED criteria) as a substitute for $\mathrm{V}$ scintigraphy have been added to reduce false-positive results from P-only planar scintigraphy. Single or multiple wedge-shaped P defects, with or without matching chest roentgenographic abnormalities,

A related article can be found at doi 10.1007/s00259-013-2425-8.

C. Schuemichen

Satower Str.4, 18059 Rostock, Germany

C. Schuemichen $(\square)$

Clinic for Nuclear Medicine, University of Rostock,

Gertrudenplatz 1, 18057 Rostock, Germany

e-mail: carl.schuemichen@med.uni-rostock.de are reported as PE-positive. Wedge-shaped areas of overperfusion usually coexist. $\mathrm{P}$ defects other than wedgeshaped are PE-negative. With pulmonary angiography as reference, the P lung scan has been shown to have a sensitivity of $92 \%$ and a specificity of $87 \%$ in the diagnosis of PE [5]. Compared to CTPA and also V/P planar scintigraphy with PIOPED II interpretation together with chest radiography, the sensitivity of P-only planar scintigraphy with PISA-PED interpretation is somewhat below $90 \%$, but diagnostic accuracy is remarkably similar [6]. Applying V/P SPECT as reference, with interpretation criteria of the European guidelines, the sensitivity of P-only SPECT with PISAPED interpretation criteria rose to an acceptable $90 \%$, and specificity to a fantastic $98 \%$. Segmental pneumonia was mentioned as a cause of false-positive findings, which could have been identified on a chest radiograph or more easily by SPECT/CT. These very promising results may be misinterpreted as an invitation to get rid of unpopular V scintigraphy.

From our own experience it seems reasonable that the appearance of secondary perfusion defects in chronic obstructive airway disease (COPD) at the lobar and segmental level may be irregular and does not follow the lobar and segmental anatomy with a frequency that, if need be, is sufficient for diagnosis of PE. However, perfusion defects at the subsegmental level are mostly not distinguishable in $\mathrm{PE}$ and COPD, and this will negatively affect the accuracy of P-only scintigraphy. In comparison with planar imaging, SPECT detects up to $83 \%$ more small perfusion defects, and an additional $21 \%$ of PE diagnoses are based on perfusion defects at the subsegmental level only [7]. This gain in sensitivity is moderately reduced by the European guidelines, since the diagnosis of $\mathrm{PE}$ requires $\mathrm{V} / \mathrm{P}$ mismatch in an area of two subsegments, both together or two separately. Using a diagnostic cut-off of one segmental or two subsegmental mismatches, a sensitivity and specificity of $92 \%$ each is obtained with V/P SPECT [8]. Taking this 
result as a basis for comparison, the effective sensitivity of Ponly SPECT will drop to $82 \%$, which cannot be rated as optimal. The question arises as to how much sensitivity is needed to keep mortality from PE low.

Recently published data may lead to the conclusion that a low sensitivity may be adequate or even helpful in preventing overdiagnosis of PE. One study indicates that the mortality risk from PE is overestimated [9]. A study in the UK found that 2,583 of 186,517 adult in-patients died, and autopsy was performed in as many as $696(27 \%)$, but in only $2.0 \%$ of these was death caused by PE [9]. In Germany, $10 \%$ of all hospital deaths are considered to be PE-related [10]. To make these numbers comparable, many variables have to be considered. Among them are comorbidity, inhouse mortality rate in an emergency department is as high as $22 \%$ [11], age (more than 65 years), ethnic origin and body mass index [12], and last but not least the duration of hospitalization. Despite anticoagulant therapy, mortality risk increases after hospital discharge, mainly due to recurrent PE. A study in the USA found an in-hospital mortality rate of $4.2 \%$ and that the 90-day mortality rate after hospital discharge increased to $13.8 \%$ [13]. A study in Iceland found a 30-day mortality rate of $9.9 \%$ [14]. In Germany approximately $10 \%$ of all patients with acute PE die during the first 1 to 3 months after diagnosis [10]. Thus, PE is still a lifethreatening disease, and early diagnosis and therapy are essential to reduce mortality.

In-hospital mortality from PE is decreasing in Europe as well in the USA, but this is not helpful either, since total mortality from PE remains constant. This has to be explained. From 2001 to 2003, in-hospital mortality from PE in Germany ranged from $20.3 \%$ to $24.4 \%$ and had decreased to $14 \%$ in 2006 [15]. From 2000 to 2007 the case-fatality index in the USA decreased from $5.7 \%$ to $3.3 \%$. In the same period the incidence of PE increased from 0.69 to 0.91 per 100 admissions [16]. Since 1998, when multidetector row CTPA was introduced in the USA, the incidence of diagnosed PE has been steadily increasing. The number of treatment complications follows this trend and the number of patients with fatal PE per diagnosed PE is decreasing, but the number of patients with fatal PE per US population remains constant [17]. It is believed that CTPA, with its greater sensitivity, detects more PE, but patients with newly diagnosed disease do not benefit from treatment since only mild PE at the subsegmental level is recognized in addition. This is called overdiagnosis and overtreatment of PE [17]. Other authors see a catastrophic problem [18].

An increase of $81 \%$ in the incidence of $\mathrm{PE}$ is believed to be largely a consequence of increased detection by CTPA, mainly at the subsegmental level [19]. However, with increasing number of detector rows the rate of isolated subsegmental PE detected by CT has increased only moderately from $4.7 \%$ to $9.4 \%$ (single versus multislice) [20], and only in younger patients to $16 \%$ [21]. Also the shift from less sensitive planar V/P scintigraphy with PIOPED interpretation to more sensitive CTPA can be held responsible for the increased incidence of PE [16]. Authors of the same working group suggest that V/P planar and V/P SPECT and CTPA have similar sensitivities, and thus have a similar impact on outcomes [22]. In a direct head-to-head comparison, the sensitivity and accuracy of planar V/P scintigraphy with revised PIOPED interpretation has been shown to be on the same level as that of CTPA [6]. With effective improvements in the sensitivity of CTPA with time, the number of positive findings per examination (prevalence) would have been expected to increase in the same way. But the opposite situation has been observed. Prevalence in the USA ranged initially from $30 \%$ to $50 \%$, but then reduced continuously and is now $10 \%$ or even below that in many institutions. and this has occurred not only for CTPA [23-26] but also for V/P scintigraphy [27]. Fear of missing PE or misdiagnosis results in a more frequent use of diagnostic tests. This trend has also been observed in Europe. In Switzerland, such defensive behaviour is frequent and is consistent with a low prevalence of positive CTPA findings [28]. The increased incidence of $\mathrm{PE}$ has been found to be strongly correlated with the increased use of CTPA [16]. The total number of examinations with CT in the USA has increased by a factor of 2.9 since 1996 [29], which is much more than the increase in the incidence of PE. A causal link - the more CTPA, the more $\mathrm{PE}$ - can only be established if PE is an underdiagnosed disease. This seems to be sufficiently proved by autopsy studies [30-33]. This extended use of CTPA is characterized by an increase in the incidence as well as a decrease in the prevalence of PE. The extended use of CTPA or V/P scintigraphy is not necessarily associated with overdiagnosis.

With limited and confusing data available, it may be difficult to calculate the therapeutic benefit from extended diagnostic tests. In outpatients with a low prevalence of PE, the mortality from untreated PE has been assumed to be $5 \%$, and the benefit-to-risk ratio has been calculated as 25 , but as 187 in inpatients with a higher prevalence of PE [33]. However, patients not examined for PE and assumed to be healthy would also be expected to benefit from extended diagnostic tests since it has been found that in patients with fatal PE, the disease was undiagnosed before death in $41.2 \%$ [30], in $57.6 \%$ [32], and (in younger patients aged $0-35$ years) in $79 \%$ [31]. Recurrent PE not diagnosed before death was additionally demonstrated in $31.4 \%$ of patients with fatal PE [30]. Mortality from previously overlooked PE is expected to decrease, but this was formerly not recognized in most cases and hence is statistically not covered. Normally, less than $10 \%$ of inpatients and many fewer outpatients undergo autopsy [34]. Thus, contrary to what has been reported, mortality in the total population may decrease from extended diagnostic tests for PE, but this cannot be proved from 
current statistics. Nevertheless, it can be assumed that the situation is less dramatic than believed [18].

The decrease in case-mortality index within the last decade can be attributed to a number of causes: (1) more mild (subsegmental) PE has been diagnosed with the more sensitive CTPA, but also the extended use of diagnostic tests may have greatly contributed to a larger proportion of mild PE, since patients with more minor symptoms have been examined; (2) implementation of more aggressive immediate therapy in submassive PE may have been beneficial; and (3) a shortened delay in diagnosis after admission to hospital would be expected to decrease mortality and may be related to better access to CTPA. One reason among others for the change from V/P scintigraphy to CTPA is 24-h availability. In a US tertiary care emergency department, the median time from arrival to diagnosis by CTPA was not more than $2.4 \mathrm{~h}$ [35], but in a corresponding hospital in Turkey the mean delay was $2.2 \pm 2.9$ days [36]. No data for V/P scintigraphy are available in this respect.

It is not the intention of this editorial to differentiate between extended use, excessive use or overuse of diagnostic tests in PE. However, casual overuse is a problem which has to be overcome by adequate quality management, not by using a diagnostic test whose sensitivity is kept artificially low. There is no rationale for going back to planar imaging, PIOPED criteria or even to P-only SPECT with PISA-PED interpretation.

In conclusion, $\mathrm{PE}$ is still best diagnosed with V/P SPECT combined with chest radiography. V/P SPECT/CT will be the future standard. The sensitivity of P-only SPECT is suboptimal and its use is only recommended in emergencies when the diagnosis of PE would otherwise be missed. However, the principle of PISA-PED interpretation can be used to further improve an already good tool, V/P SPECT, to a high level, as documented in the European guidelines [1, 2].

\section{References}

1. Bajc M, Neilly JB, Miniati M, Schuemichen C, Meignan M, Jonson B. EANM guidelines for ventilation /perfusion scintigraphy: Part 1. Pulmonary imaging with ventilation perfusion single photon emission tomography. Eur J Nucl Med Mol Imaging. 2009;36(8):135670.

2. Bajc M, Neilly JB, Miniati M, Schuemichen C, Meignan M, Jonson B. EANM guidelines for ventilation/perfusion scintigraphy: Part 2. Algorithms and clinical considerations for diagnosis of pulmonary emboli with V/P(SPECT) and MDCT. Eur J Nucl Med Mol Imaging. 2009;36(9):1528-38.

3. Gutte H, Mortensen J, Jensen CV, Johnbeck CB, von der Recke P, Petersen CL, et al. Detection of pulmonary embolism with combined ventilation-perfusion SPECT and low-dose CT: head-to-head comparison with multidetector CT angiography. J Nucl Med. 2009;50(12):1987-92.

4. Reid JH, Coche EE, Inoue T, Kim EE, Dondi M, Watanabe N, et al. Is the lung scan alive and well? Facts and controversies in defining the role of lung scintigraphy for the diagnosis of pulmonary embolism in the era of MDCT. Eur J Nucl Med Mol Imaging. 2009;36(3):505-21.

5. Miniati M, Pistolesi M, Marini C, Di Ricco G, Formichi B, Prediletto R, et al. Value of perfusion lung scan in the diagnosis of pulmonary embolism: results of the prospective Investigative Study of Pulmonary Embolism Diagnosis (PISA-PED). Am J Respir Crit Care Med. 1996;154(5):1387-93.

6. He J, Wang F, Dai HJ, Li M, Wang Q, Yao Z, et al. Chinese multicenter study of lung scintigraphy and CT pulmonary angiography for the diagnosis of pulmonary embolism. Int $\mathrm{J}$ Cardiovasc Imaging. 2012;28(7):1799-805.

7. Reinartz P, Wilberger JE, Schaefer W, Nowak B, Mahnken AH, Buell $\mathrm{U}$. Tomographic imaging in the diagnosis of pulmonary embolism: a comparison between V/Q lung scintigraphy in SPECT technique and multislice spiral CT. J Nucl Med. 2004;45(9):1501-8

8. Le Roux PY, Robin P, Delluc A, Abgral R, Le Duc-Pennec A, Nowak E, et al. V/Q SPECT interpretation for pulmonary embolism diagnosis: which criteria to use? J Nucl Med. 2013. doi:10.2967/ jnumed.112.113639.

9. Koppke D, Harryman O, Bebow EW, Hay C, Chalmers N. Mortality from pulmonary embolism is decreasing in hospital patients. J R Soc Med. 2011;104(8):327-31.

10. Lankeit M, Konstatinides S. Mortality risk assessment and the role of thrombolysis in pulmonary embolism. Crit Care Clin. 2011;27(4):953-67.

11. Scarvelis D, Anderson J, Davis L, Forgie M, Lee J, Petersson L, et al. Hospital mortality due to pulmonary embolism and an evaluation of the usefulness of preventative interventions. Thromb Res. 2010;125(2):166-70.

12. Tang Y, Sampson B, Pack S, Shah K, Yon Um S, Wang D, et al. Ethnic differences in out-of-hospital fatal pulmonary embolism. Circulation. 2011;123(20):2219-25.

13. Fanikos J, Rao A, Seger AC, Carter D, Piazza G, Goldhaber SZ. Hospital costs of acute pulmonary embolism. Am J Med. 2013;126(2):127-32.

14. Jonsson KO, Agnarsson UT, Danielsen R, Thorgeirsson G. Pulmonary embolism at Landspítali, the National University Hospital of Iceland 2005-2007 - incidence, clinical manifestations, risk factors and outcome. Laeknabladid. 2013;99(1):11-5

15. Kröger K, Küpper-Nybelen J, Moerchel C, Moysidis T, Kienitz C, Schubert I. Prevalence and economic burden of pulmonary embolism in Germany. Vasc Med. 2012;17(5):303-9.

16. Sheh SH, Bellin E, Freemann KD, Haramati LB. Pulmonary embolism diagnosis and mortality with $\mathrm{CT}$ angiography versus ventilation-perfusion scintigraphy; evidence of overdiagnosis with CT? AJR Am J Roentgenol. 2012;198(6):1340-5.

17. Wiener RS, Schwartz LM, Woloshin S. Time trends in pulmonary embolism in the United States: evidence of overdiagnosis. Arch Intern Med. 2011;171(9):831-7

18. Winters BS, Solarz M, Jacovides CL, Purtill JJ, Rothmann RH, Parvizi L. Overdiagnosis of pulmonary embolism: evaluation of a hypoxia algorithm designed to avoid this catastrophic problem. Clin Orthop Relat Res. 2012;470(2):497-502.

19. Burns SK, Haramati LB. Diagnostic imaging and risk stratification of patients with acute pulmonary embolism. Cardiol Rev. 2012;20(1):15-24.

20. Carrier M, Righini M, Wells PS, Perrier A, Anderson DR, Rodger MA, et al. Subsegmental pulmonary embolism diagnosed by computed tomography: incidence and clinical implications. A systematic review and meta-analysis of the management and outcome studies. J Thromb Haemost. 2010;8(8):1716-22.

21. Lee EY, Neumann MI, Lee NJ, Johnson VM, Zurakowski D, Tracy DA, et al. Pulmonary embolism detected by pulmonary MDCT angiography in older children and young adults: risk factor assessment. AJR Am J Roentgenol. 2012;189(6):1431-7. 
22. Freeman LM, Glaser JE, Haramati LB. Planar ventilation-perfusion imaging for pulmonary embolism: the case for "outcomes" medicine. Semin Nucl Med. 2012;42(1):3-10.

23. Vedovati MC, Becattini C, Agnelli G, Kamphuisen PW, Masotti L, Pruszczyk P, et al. Multidetector CT scan for acute pulmonary embolism: embolic burden and clinical outcome. Chest. 2012;142(6):1417-24.

24. Adams DM, Stevens SM, Woller SC, Evans RS, Lloyd JF, Snow GL, et al. Adherence to PIOPED II investigators' recommendations for computed tomography pulmonary angiography. Am J Med. 2013;126(1):36-42.

25. Raja AS, Ip IK, Prevedello LM, Sodickson AD, Farkas C, Zane $\mathrm{RD}$, et al. Effect of computerized clinical decision support on the use and yield of CT pulmonary angiography in the emergency department. Radiology. 2012;262(2):468-74.

26. Mitchell AM, Jones AE, Tumlin JA, Kline JA. Prospective study of the incidence of contrast-induced nephropathy among patients evaluated for pulmonary embolism by contrast-enhanced computed tomography. Acad Emerg Med. 2012;19(6):618-25.

27. Glaser JE, Hamarthy M, Haramati LB, Essens D, Freeman LM. Successful and safe implantation of a trinary interpretation and reporting strategy for $\mathrm{V} / \mathrm{Q}$ lung scintigraphy. J Nucl Med. 2011;52(10):1508-12.

28. Rohazek M, Buatsi J, Suzuks-Farkas Z, Kleim B, Zimmermann H, Exadaktylos A, et al. Ordering CT pulmonary angiography to exclude pulmonary embolism: defense versus evidence in the emergency room. Intensive Care Med. 2012;38(8):1345-51.
29. Smith-Bindman R, Miglioretti DL, Johnson E, Lee C, Feigelson HS, Fynn M, et al. Use of diagnostic imaging studies and associated radiation exposure for patients enrolled in large integrated health care systems, 1996-2010. JAMA. 2012;307(22):2400-9

30. Reissig A, Haase U, Schulze E, Lehmann T, Kroegel C. Diagnosis and therapy of pulmonary embolism prior to death. Dtsch Med Wochenschr. 2010;135(30):1477-83.

31. Theilade J, Winkel BG, Holst AG, Tfelt-Hansen J, Svendsen JH, Haunsø S. A nationwide, retrospective analysis of symptoms, comorbidities, medical care and autopsy findings in cases of fatal pulmonary embolism in younger patients. $\mathrm{J}$ Thromb Haemost. 2010;8(8):1723-9.

32. Gradistanac T, Wittekind D. Autopsy as a tool for quality insurance. Leipzig Pathol. 2011;32 Suppl 2:287-91.

33. Woo JK, Chiu RY, Thakur Y, Mayo JR. Risk-benefit analysis of pulmonary CT angiography in patients with suspected pulmonary embolus. AJR Am J Roentgenol. 2012;198(6):1332-9.

34. Perkins GD, McAuel DF, Davies S, Gao F. Discrepancies between clinical and postmortem diagnoses in critically ill patients: an observational study. Crit Care. 2003;7(6):R22129-32.

35. Smith SB, Geske JB, Morgenthaler TI. Risk factors associated with delayed diagnosis of acute pulmonary embolism. J Emerg Med. 2012;42(1):1-6.

36. Aydoğdu M, Doğan NÖ, Sinanoğlu NT, Oğuzülgen İK, Demircan A, Bildik F, et al. Delay in diagnosis of pulmonary thromboembolism in emergency department: is it still a problem? Clin Appl Thromb Hemost. 2012. doi:10.1177/1076029612440164. 